\title{
Study on the Dynamic Strategies of Differential Game of Water Pollution Control from the View of Public Participation
}

\author{
Zhenyun $\mathrm{Hu}$ \\ a. State Key Laboratory of Hydrology-Water Resources \\ and Hydraulic Engineering, Hohai University; b. Business \\ school, Hohai University; c. Institute of Management \\ Science, Hohai University \\ Nanjing, China \\ z_y_hu@sina.com
}

\author{
Chen Chen \\ Business school, Hohai University \\ Nanjing, China \\ Chenchen6439@sina.com
}

\begin{abstract}
Water pollution control is a systematic engineering which needs the whole society to participate in, especially the public participation. This paper develops a continuous-time differential game of water pollution control between government and the public with the consideration of dynamic change of pollutants in the rivers. The public determines participation efforts and the government determines its enforcement level. And we obtain a set of feedback Nash equilibrium for the problem. Through analysis on the properties of the equilibrium solutions, some results are derived: The efforts of public participation is positively related to the enforcement level of government; When the government gives a reasonable bonus to the citizens who do well in reporting pollution behaviors of entrepreneurs, increasing bonus will induce an increase of the efforts of public participation. Finally, we make some suggestions to improve the public participation efforts in the water pollution control.
\end{abstract}

keywords-public participation; water pollution control; differential game; feedback Nash equilibrium

\section{INTRODUCTION}

As an important natural resource and economic resource, water plays a very important role in the development of our economy. With the rapid economic development of our country, the problem of water pollution has endangered the health and life safety of the people. The worsening of water pollution shows that just relying on the government intervention and market mechanism cannot solve the problem of water pollution fundamentally. So we need to encourage the public to participate in the water pollution control.

The studies of public participation in water pollution control date back to 1950s.Scholars analyze the public participation in areas such as the ways, effectiveness, advantages and disadvantages. Seidenberg and Jennifer L pointed out that much of the Act's effectiveness in cleaning up the nation's waterways can be attributed to its public participation and citizen suit provisions, which have filled gaps in the often reluctant enforcement capabilities of the Environmental Protection Agency (EPA) and state agencies [1]. Steven E.Daniels applied the Vroom-Yetton model to analyze the effectiveness of public participation in decision-making and ecosystem-based management [2]. Clark shown that the public participation cost of environmental protection is lower than governmental regulation cost of that and public participation could achieve the same or better environmental objectives through analysis of the data of EPA voluntary program [3]. Britta Kastens and Jens Newig explored the role of the "active involvement" of stakeholders in reducing agricultural nitrate pollution of groundwater and emphasized three factors that lead to successful involvement process: seriousness of the process, commitment of stakeholders, role of environmental NGOs [4]. Maiello Antonella highlighted the existence of concurrent policy mechanisms in the same local environment, which undermines the results of public participation and stressed a politicized organization of the public engagement process so that local environmental governance achieves sustainability [5].

Some scholars applied game theory to analyze the water pollution control of public participation. But most of these games are static game and evolutionary game [6-8]. These studies didn't take the changes of pollution stock into account. However, differential games cover this shortage and provide an effective tool to study water pollution problem and to analyze the interactions between gamers' strategic behaviors within taking the changes of pollution into account. And the feedback Nash Equilibrium (FBNE) is derived in a dynamic programming framework, so that controls depend on time and state, and the solution is Markov perfect by construction. Therefore, the feedback Nash Equilibrium (FBNE) is more satisfactory [9]. In this paper, we develop a continuous-time differential game of water pollution control between government and the public. Furthermore, we analyze the properties of the equilibrium solutions and make some suggestions to encourage the citizens to participate in water pollution control.

\section{GAME FORMULATION}

Consider a game with two decision makers-the government and the public, whose planning horizon is $\left[t_{0}, t\right]$. And they both have the same discounted rate $\rho$.The pollution in the river is generated in the process of production. Let $q$ be 
the level of entrepreneurs' production. As a result of production, entrepreneurs emit a quantity $e=f(q)$ of pollutants, so the revenue that entrepreneurs derive from the production can be expressed by the function of $e$.The public will inform on the entrepreneurs who discharge pollution illegally. And with the consideration of the administrators' time, energy and prosecution cost, it is not $100 \%$ certain that the government will be able to prosecute every case and may only prosecute a fraction of the incidences that are reported to them. For the sake of mathematical tractability, we assume that the cost function $C_{1}(\cdot)$ of public participation and the operating cost function $C_{2}(\cdot)$ of government have the following properties: $C_{1}^{\prime}>0, C_{1}^{\prime \prime}>0, C_{2}^{\prime}>0, C_{2}^{\prime \prime}>0$. Since it is well known that the actual damage of pollution in river to the governments and the public cannot be measured precisely, we elect to use a linear approximation of such measurements.

\subsection{Pollution Dynamics}

Entrepreneurs' production emits pollutants into the river and the government does some pollution abatement to reduce pollutants existing in the river according to the public whistleblowing. Let $P(s)$ denote the level of pollution in the river at time $s$.The dynamics of pollution stock in the river is governed by the differential equation:

$$
\begin{gathered}
\dot{P}(s)=e-k_{1} \alpha(s)-k_{2} \beta(s)-\delta P(s) \\
P\left(s_{0}\right)=P_{0}
\end{gathered}
$$

Where $e-k_{1} \alpha(s)$ is the amount of pollution emitted into river by entrepreneurs, $e$ is the amount of pollutants created by entrepreneurs output. Under the pressure of public participation, the entrepreneurs will cut quantity $k_{1} \alpha(s)$ of pollutants. $\alpha(s)$ denotes the effort of the public participation. $k_{1}$ is the coefficient of entrepreneurs' pollutants reduction. $\beta(s)$ is the government's enforcement level to the public whistle-blowing. $k_{2} \beta(s)$ is the amount of pollution removed by $\beta(s)$ unit of enforcement level of government. $\delta$ is the nature's absorption rate of the river and the initial level of pollution $P(s)$ at time $s_{0}$ in the river is known and equals $P_{0}$.

\subsection{The Public Ojectives}

The public which obtain rewards from government and at the same time handle the cost of reporting and suffer from water pollution, attempts to maximize the payoff function

$$
\int_{t_{0}}^{t}\left(\alpha(s) \beta(s) \omega-\frac{c_{1}}{2} \alpha(s)^{2}-\mu P(s)\right) e^{-\rho\left(s-t_{0}\right)} d s
$$

By choosing the participation efforts $\alpha(s)$.

Where $\alpha(s) \beta(s) \omega$ are the rewards that citizens obtain from the government, including material rewards and spiritual rewards. And the amount of the rewards is affected by the level of governments' enforcement $\beta(s) . \omega$ is coefficient of rewards. $\frac{c_{1}}{2} \alpha(s)^{2}$ is the cost of public participation, such as the massive amount of time and money that citizens has spent in reporting, where $c_{1}>0 . \mu P(s)$ is the value of damage to health and quality of public life from $P(s)$ amount of pollution, where $\mu>0$.

\subsection{Government Ojectives}

The government has to promote business interest and at the same time handle the financing of the costs brought about by pollution. So government selects a level of enforcement to handle the citizen's reporting $\beta(s)$ which maximizes

$$
\int_{t_{0}}^{t}\left(a e+\gamma \alpha(s) \beta(s)-\frac{c_{2}}{2} \beta(s)^{2}-\alpha(s) \beta(s) \omega-\theta P(s)\right) e^{-\rho\left(s-t_{0}\right)} d s
$$

Where $a e$ are the gains of the entrepreneurs' production. According to the level of the local government's enforcement and the efforts of public participation, the superior government will give a bonus to the local government which equals $\gamma \alpha(s) \beta(s), \gamma$ is the bonus coefficient. $\frac{c_{2}}{2} \beta(s)^{2}$ is the operating cost of local government, where $c_{2}>0 . \alpha(s) \beta(s) \omega$ is the bonus expenditures. $\theta P(s)$ is the value of damage to the local economy and the health of the citizens from $P(s)$ amount of pollution, where $\theta>0$.

\subsection{Nash Equilibrium Solution}

To ensure there is only one continuous solution $P(s)$ existing in (1), we need to formulate a set of bounded continuous differentiable value functions $V_{c}(P)$ and $V_{g}(P)$.And the formulation of the Hamilton-Jacobi-bellman (HJB) equations are written as follows:

$$
\begin{aligned}
& \rho V_{c}(P)=\underset{\alpha(s) \geq 0}{\operatorname{Max}}\left(\alpha(s) \beta(s) \omega-\frac{c_{1}}{2} \alpha(s)^{2}-\mu P(s)+\right. \\
& \left.V_{c}^{\prime}(P)\left(e-k_{1} \alpha(s)-k_{2} \beta(s)-\delta P(s)\right)\right) \\
& \rho V_{g}(p)=\underset{\beta(s) \geq 0}{\operatorname{Ma}}\left(a e+\gamma \alpha(s) \beta(s)-\frac{c_{2}}{2} \beta(s)^{2}-\alpha(s) \beta(s) \omega\right. \\
& \left.-\theta P(s)+V_{g}^{\prime}(P)\left(e-k_{1} \alpha(s)-k_{2} \beta(s)-\delta P(s)\right)\right)
\end{aligned}
$$

Performing the indicated maximization in (4) yields

$$
\beta(s) \omega-c_{1} \alpha(s)-k_{1} V_{c}^{\prime}(P)=0
$$

Then, performing the indicated maximization in (5) yields

$$
\gamma \alpha(s)-c_{2} \beta(s)-\alpha(s) \omega-k_{2} V_{g}^{\prime}(P)=0
$$




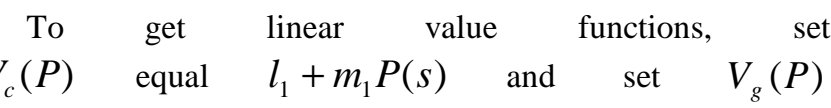
equal $l_{2}+m_{2} P(s)$, where $l_{1}, m_{1}, l_{2}, m_{2}$ are constants. Substituting $V_{c}^{\prime}(P)=m_{1}, V_{g}^{\prime}(P)=m_{2}$ in (4) and (5) respectively yields:

$$
\begin{aligned}
& \rho\left(l_{1}+m_{1} P(s)\right)=\alpha(s) \beta(s) \omega-\frac{c_{1}}{2} \alpha(s)^{2}-\mu P(s) \\
& +m_{1}\left(e-k_{1} \alpha(s)-k_{2} \beta(s)-\delta P(s)\right) \\
& \rho\left(l_{2}+m_{2} P(s)\right)=a e+\gamma \alpha(s) \beta(s)-\frac{c_{2}}{2} \beta(s)^{2}-\alpha(s) \beta(s) \omega \\
& -\theta P(s)+m_{2}\left(e-k_{1} \alpha(s)-k_{2} \beta(s)-\delta P(s)\right)
\end{aligned}
$$

Then we can get that:

$$
\begin{gathered}
\rho m_{1} P(s)=-\mu P(s)-m_{1} \delta P(s) \\
m_{1}=\frac{-\mu}{\rho+\delta} \\
\rho m_{2} P(s)=-\theta P(s)-m_{2} \delta P(s) \\
m_{2}=\frac{-\theta}{\rho+\delta} \\
\operatorname{So}_{c}^{\prime}(P)=m_{1}=\frac{-\mu}{\rho+\delta}, V_{g}^{\prime}(P)=m_{2}=\frac{-\theta}{\rho+\delta}
\end{gathered}
$$

Substituting the values of $m_{1}$ and $m_{2}$ respectively into (6) and (7) yields:

$$
\begin{gathered}
\beta(s) \omega-c_{1} \alpha(s)+\frac{\mu k_{1}}{\rho+\delta}=0 \\
\gamma \alpha(s)-c_{2} \beta(s)-\alpha(s) \omega+\frac{\theta k_{2}}{\rho+\delta}=0
\end{gathered}
$$

Solve this pair of simultaneous equations. A set of feedback Nash equilibrium strategies $\left[\alpha^{*}(s), \beta^{*}(s)\right]$ for the game (1), (2) and (3) can be obtained as follows:

$$
\begin{gathered}
\alpha^{*}(s)=\frac{\left.-\theta \omega^{2} k_{1}+(\theta) k_{1}+\mu c_{1} k_{2}\right) \omega}{c_{1}(\rho+\delta)\left(\omega^{2}-\omega \gamma+c_{1} c_{2}\right)}+\frac{k_{1} \theta}{c_{1}(\rho+\delta)} . \\
\beta^{*}(s)=\frac{-\theta \omega k_{1}+\theta j k_{1}+\mu c_{1} k_{2}}{(\rho+\delta)\left(\omega^{2}-\omega \gamma+c_{1} c_{2}\right)} .
\end{gathered}
$$

\section{ANALYSIS ON THE PROPERTIES OF THE EQUILIBRIUM SOLUTIONS}

Proposition 1 the efforts of public participation is positively related to the level of the government's enforcement
Proof

Differentiating (8) with respect to $\beta(s)$ leads to $\frac{\partial \alpha(s)}{\partial \beta(s)}=\frac{\omega}{c_{1}}$. Since $c_{1}>0$ and $\omega>0, \frac{\partial \alpha(s)}{\partial \beta(s)}>0$.That is, the efforts of public participation $\alpha(s)$ is positively related to the level of the government's enforcement $\beta(s)$, which indicates that an increase in the level of the government's enforcement will increase the efforts of public participation. It reflects that if government attaches more importance to the public reporting and handling it without delay, the public will have more enthusiasm to report entrepreneurs' illegal behavior of discharging pollution to the government, which can improve the situation of water pollution.

Proposition 2 when the government's bonus level $\omega$ is in the

$$
\begin{gathered}
{\left[\frac{-\theta k_{1} c_{1} c_{2}-\sqrt{\theta^{2} k_{1}{ }^{2} c_{1}{ }^{2} c_{2}{ }^{2}+c_{1}{ }^{2} c_{2} k_{2} \mu\left(\theta j k_{1}+\mu c_{1} k_{2}\right)}}{\mu c_{1} k_{2}},\right.} \\
\left.\frac{-\theta k_{1} c_{1} c_{2}+\sqrt{\theta^{2} k_{1}{ }^{2} c_{1}{ }^{2} c_{2}{ }^{2}+c_{1}{ }^{2} c_{2} k_{2} \mu\left(\theta \gamma k_{1}+\mu c_{1} k_{2}\right)}}{\mu c_{1} k_{2}}\right],
\end{gathered}
$$

the equilibrium efforts of public participation $\alpha^{*}(s)$ is positively related to the government's bonus level $\omega$

Proof to

Differentiating (10) with respect to $\omega$ leads

$$
\begin{aligned}
& \frac{\partial \alpha^{*}(s)}{\partial \omega}=\frac{-\mu c_{1} k_{2} \omega^{2}-2 \theta k_{1} c_{1} c_{2} \omega+c_{1} c_{2}\left(\theta \gamma k_{1}+\mu c_{1} k_{2}\right)}{c_{1}(\rho+\delta)\left(\omega^{2}-\omega \gamma+c_{1} c_{2}\right)^{2}} \\
& \text { So when } \frac{\omega \text { is in the region }}{\left[\frac{-\theta k_{1} c_{1} c_{2}-\sqrt{\theta^{2} k_{1}{ }^{2} c_{1}{ }^{2} c_{2}{ }^{2}+c_{1}{ }^{2} c_{2} k_{2} \mu\left(\theta \gamma k_{1}+\mu c_{1} k_{2}\right)}}{\mu c_{1} k_{2}}\right.} \\
& \left.\frac{-\theta k_{1} c_{1} c_{2}+\sqrt{\theta^{2} k_{1}{ }^{2} c_{1}{ }^{2} c_{2}{ }^{2}+c_{1}{ }^{2} c_{2} k_{2} \mu\left(\theta j k_{1}+\mu c_{1} k_{2}\right)}}{\mu c_{1} k_{2}}\right]
\end{aligned}
$$

$\frac{\partial \alpha^{*}(s)}{\partial \omega}>0$.It indicates that when $\omega$ is in the region above,

the equilibrium efforts of public participation is positively related to the government's bonus level $\omega$, that is, as the government increases the bonus level, the public will have more enthusiasm to participate in the water pollution control. So it reflects that the government should make its bonus within in reasonable region, thus the increasing bonus could have a positive effect on the efforts of public participation.

Proposition3 when $\gamma>2 \sqrt{c_{1} c_{2}}$, the equilibrium level of local government's enforcement $\beta^{*}(s)$ is positively related to the bonus level of superior government $\gamma$ Proof 
Differentiating (11) with respect to $\gamma$ leads to $\frac{\partial \beta^{*}(s)}{\partial \gamma}=\frac{\theta k_{1}}{(\rho+\delta)\left(\omega^{2}-\omega \gamma+c_{1} c_{2}\right)} \quad$.So when
$\gamma>2 \sqrt{c_{1} c_{2}}, \frac{\partial \beta^{*}(s)}{\partial \gamma}>0 \quad$.It indicates that when $\gamma>2 \sqrt{c_{1} c_{2}}$, the equilibrium level of local government's enforcement $\beta^{*}(s)$ is positively related to the bonus level of superior government $\gamma$, that is ,as the superior government increases the bonus level, the local government will also increase its enforcement level.

\section{CONCLUSIONS}

Through the analysis, we can know that public participation could restrain the emissions of entrepreneurs effectively. To encourage the public to participate in the water pollution control, we make some suggestions as follows:

First, the government should strengthen enforcement to improve the efforts of public participation. Government's enforcement is a key factor to the efforts of public participation in water pollution control. The ignorance to the public reporting will greatly dampened the enthusiasm of the public participation. Therefore, the government should strengthen enforcement in the water pollution incident which public has reported to them and develop a good feedback mechanism. When the public feedback is replied timely, they will have more enthusiasm to inform against the entrepreneurs who discharge pollution illegally. Besides, government could take advantage of NGO to monitor the environmental pollution problems, thus improving its efficiency of dealing with the public whistle-blowing. Owing to the limitation of time and energy, government can't deal with every public whistleblowing. However, NGO has excellent experts with professional environmental knowledge, so government could establish a constructive and cooperative partnership with NGO to improve its work efficiency.

Second, the government should perfect the incentive mechanism and give a reasonable bonus to improve the efforts of public participation. Government need to perfect the incentive mechanism to encourage the public to participate in the water pollution control. For example, the government could set up an environmental prize to praise citizens who do well in public participation. Because unreasonable bonus will have a negative effect on the efforts of public participation, the government should make sure the bonus is within the region mentioned above. At the same time, the government should keep the reporters' personal information secret so that reporters will not be attacked or retaliated. Besides, the government may establish a feedback mechanism to make the public feel that government really attaches importance to their whistle-blowing. So the public will have more enthusiasm to participate in water pollution control.

\section{ACKNOWLEDGMENT}

This research was supported by the State Key Program Fund of National Social Science of China (Grant no.12\&ZD214), the Public Welfare Fund of the Ministry of Water Resources (Grant no.200901068) and the Social Science Fund of Jiangsu Province(Grant no.09SHB003).

\section{REFERENCES}

[1] Seidenberg, Jennifer, "Texas independent producers \& royalty owners ass'n v. Environmental protection agency. Redefining the role of public participation in the Clean Water Act," Ecology Law Quarterly, vol. 33, pp. 699-724, 2006.

[2] Steven E.Daniels, Rick L.Lawrence, Ralph J.Alig, "Decision-making and ecosystem-based management: Applying the Vroom-Yetton model to public participation strategy," Environmental Impact Review, pp. 1330, 1996.

[3] Clark M, "Corporate environmental behavior research:informing environmental policy," Structural Change and Economic Dynamics, vol. 16, pp.422-431, 2005.

[4] Britta Kastens, Jens Newig, "Will participation foster the successful implementation of the water framework directive? The case of agricultural groundwater protection in northwest Germany," Local Environment, vol. 13, pp. 27-41, 2008.

[5] Maiello A, Christovão A C, Nogueira de Paiva Britto A L, Frey M, "Public participation for urban sustainability: investigating relations among citizens, the environment and institutions-an enthnographic study," Local Environment, vol. 18, pp. 167-183, 2013.

[6] Ming Li, Chuang Lin Fang, Yu Shi, "Game effects in regional governance," China Population, Resources and Environment, vol. 18, pp. $1-7,2008$.

[7] Ke Wang, Jun Bi, Bing Zhang, "Game-analysis of rent-seeking in environment regulation: A case study of compensated use of emission permits policy," China Population, Resources and Environment, vol. 20, pp. 95-99, 2010

[8] Yan Wang, De Wen Ding, "Game analysis of public participation in environmental protection," Journal of Dalian Maritime University, vol. 32, pp. 19-22, 2006.

[9] G.Kossioris, M. Plexousakis, A. Xepapadeas, A. de Zeeuw, K.-G. Ma ler, "Feedback Nash equilibria for non-linear differential games in pollution control," Journal of Economic Dynamics \& Control, pp. 1312-1331, 2008. 